\title{
Alterações anatômicas e físico-químicas associadas ao armazenamento refrigerado de pêssegos 'Aurora-1' e 'Dourado-2'(1)
}

\author{
Ilana Urbano Bron ${ }^{(2)}$, Angelo Pedro Jacomino(3) e Beatriz Appezzato-da-Glória ${ }^{(2)}$
}

\begin{abstract}
Resumo - O presente trabalho objetivou avaliar as características anatômicas e físico-químicas de pêssegos (Prunus persica (L.) Batsch) 'Aurora-1' e 'Dourado-2', armazenados em diferentes temperaturas e períodos. No primeiro experimento, os frutos foram armazenados a 0,3 e $6^{\circ} \mathrm{C}$ por $14,21,28$ e 35 dias (mais dois dias de simulação à comercialização, sob $25^{\circ} \mathrm{C}$ ). No segundo experimento, os frutos foram armazenados a 0 e $3^{\circ} \mathrm{C}$ por 7, 14, 21, 28 e 35 dias (mais dois dias de simulação à comercialização, sob $25^{\circ} \mathrm{C}$ ). $\mathrm{O}$ delineamento experimental empregado foi inteiramente ao acaso, em esquema fatorial, com quatro repetições em parcelas de seis frutos. Pêssegos 'Dourado-2', após sete dias de armazenamento a $3^{\circ} \mathrm{C}$ ou 14 dias de armazenamento a $0^{\circ} \mathrm{C}$, apresentaram lanosidade caracterizada pela queda brusca na firmeza e pouca sucosidade. Os sintomas no mesocarpo foram caracterizados pelo afastamento das paredes de células adjacentes e acúmulo de substâncias pécticas no interior das células e dos espaços intercelulares. Pêssegos 'Aurora-1' sofreram redução na firmeza sem comprometer a qualidade dos frutos, podendo ser conservados por até 35 dias a 0 e $3^{\circ} \mathrm{C}$; mesmo aos 35 dias de armazenamento, o mesocarpo não apresentou alterações típicas da lanosidade. Aos 35 dias de armazenamento a $6^{\circ} \mathrm{C}$, os frutos de ambas cultivares estavam sobremaduros.
\end{abstract}

Termos para indexação: Prunus persica, propriedade físico-química, anatomia vegetal, conservação de alimento, distúrbio fisiológico, lanosidade.

\section{Anatomical and physico-chemical alterations associated with cold storage of 'Aurora-1' and 'Dourado-2' peaches}

\begin{abstract}
The objective of the present study was to evaluate the anatomical and physico-chemical characteristics of 'Aurora-1' and 'Dourado-2' peaches (Prunus persica (L.) Batsch) stored at different temperatures and periods. In the first experiment, fruits were stored at 0,3 and $6^{\circ} \mathrm{C}$ for $14,21,28$ and 35 days (more two days of simulated commercialization period at $25^{\circ} \mathrm{C}$ ). In the second experiment, fruits were stored at 0 and $3^{\circ} \mathrm{C}$ for $7,14,21,28$ and 35 days (more two days at $25^{\circ} \mathrm{C}$ of simulated commercialization period). The experiment was a factorial with a completely randomized design with four replicates with six fruit parcels. 'Dourado-2' peaches after seven days of storage at $3^{\circ} \mathrm{C}$ or 14 days of storage at $0^{\circ} \mathrm{C}$ showed woolliness characterized by a sharp decrease in firmness and low juice content. The mesocarp symptoms were characterized by a separation of cell walls, pectin accumulation into the cells and intercellular spaces. 'Aurora-1' peaches lost firmness without compromising fruit quality; they could be conserved for up to 35 days at 0 or $3^{\circ} \mathrm{C}$; even at 35 days of storage, mesocarp did not present typical alterations of woolliness. At 35 days of storage at $6^{\circ} \mathrm{C}$, the fruits of both cultivars were overripe.
\end{abstract}

Index terms: Prunus persica, physico-chemical trait, vegetal anatomy, food conservation, physiological disturbs, woolliness.

(1) Aceito para publicação em 28 de maio de 2002 .

Apoio financeiro da Capes, da Fapesp e do CNPq.

(2) Escola Superior de Agricultura Luiz de Queiroz (Esalq), Dep. de Ciências Biológicas, Caixa Postal 9, CEP 13418-900 Piracicaba, SP. E-mail: iubron@esalq.usp.br, bagloria@esalq.usp.br

(3) Esalq, Dep. de Produção Vegetal.

E-mail: jacomino@esalq.usp.br

\section{Introdução}

O armazenamento em baixas temperaturas imediatamente após a colheita é a técnica mais usada para prolongar a conservação dos frutos. Com a redução da temperatura, as reações enzimáticas, principalmente as associadas à respiração e senescência, ocor- 
rem mais lentamente. A diminuição da atividade respiratória, principal processo fisiológico pós-colheita, propicia, em decorrência, menores perdas de aroma, sabor, textura, cor e outros atributos de qualidade dos frutos (Chitarra \& Chitarra, 1990). No armazenamento refrigerado de pêssegos e nectarinas, as temperaturas recomendadas variam de $-0,5$ a $0^{\circ} \mathrm{C}$ (Galindo et al., 1992). Nessas condições, os frutos podem ser conservados por duas a quatro semanas (Chitarra \& Chitarra, 1990).

Assim como acontece com a maioria dos produtos de hortifruticulturas, $\mathrm{o}$ armazenamento refrigerado dos pêssegos é limitado por lesões causadas pelo frio, chamadas, genericamente, pelo anglicismo "chilling"; geralmente se evidenciam em cultivares de polpa mais sensível, após duas ou três semanas em armazenamento, desde temperaturas acima do ponto de congelamento $\left(-0,5^{\circ} \mathrm{C}\right)$ até inferiores a $10^{\circ} \mathrm{C}$ (Lill et al., 1989; Luchsinger \& Walsh, 1998). Mesmo não provocando o congelamento das células, a exposição dos frutos a baixas temperaturas por determinado período pode causar uma série de modificações no metabolismo normal, que prejudicam a qualidade dos produtos. Os sintomas típicos de "chilling" em pêssegos tornam-se visíveis quando os frutos são transferidos para temperaturas mais altas que permitam seu amadurecimento. Tais sintomas são caracterizados pelo escurecimento da polpa, aumento da susceptibilidade a podridões, perda do sabor e aroma característicos, e lanosidade (Morris, 1982; Von Mollendorff \& Villiers, 1988; Crisosto et al., 1999).

Em pêssegos, o "chilling” se evidencia principalmente pela lanosidade (Fernández-Trujillo et al., 1998), que se caracteriza por um distúrbio fisiológico que ocorre durante o amadurecimento do fruto, depois de um período de armazenamento em temperaturas inferiores a $8^{\circ} \mathrm{C}$ (Buescher \& Furmanski, 1978). Bramlage (1982) observou que pêssegos e nectarinas conservados por mais de duas semanas sob temperaturas entre 0 e $5^{\circ} \mathrm{C}$ desenvolveram lanosidade durante o amadurecimento. Von Mollendorff et al. (1992) constataram lanosidade em nectarinas quando estas foram armazenadas a $-0,5$ ou $3^{\circ} \mathrm{C}$ por três ou quatro semanas. Até duas semanas de armazenamento nessas condições, nenhum sintoma foi observado.
A identificação da lanosidade é bastante problemática, uma vez que não há diferenças aparentes entre frutos sadios e frutos lanosos. Os sintomas são perceptíveis apenas quando a polpa do fruto é seccionada, ou seja: o problema não é observado até que o fruto seja consumido (Bruhn et al., 1991; Luchsinger \& Walsh, 1998). Outra dificuldade é que a lanosidade só é identificada após a remoção do fruto do armazenamento refrigerado.

O sintoma de lanosidade, que geralmente se expressa a partir da segunda semana de armazenamento, é caracterizado por polpa seca e farinhenta, perda de sabor e firmeza, e ausência de sucosidade (Lill et al., 1989).

O método mais eficiente na prevenção e posterior controle de desordens fisiológicas consiste na identificação das causas que as induzem, bem como a progressão desses distúrbios durante o armazenamento refrigerado.

O conhecimento do potencial de conservação dos frutos de determinada cultivar é essencial, para que possam ser desenvolvidas técnicas adequadas para os procedimentos de seleção e embalagem, de armazenamento e comercialização, orientando produtores e intermediários na elaboração de uma estratégia mais eficiente na pós-colheita.

O objetivo deste trabalho foi avaliar as alterações anatômicas e fisiológicas associadas a temperaturas e períodos de armazenamento no potencial de conservação de pêssegos das cultivares Aurora-1 e Dourado-2.

\section{Material e Métodos}

Os pêssegos (Prunus persica (L.) Batsch) utilizados no experimento foram das cultivares Aurora-1 e Dourado-2, colhidos em pomar comercial do Município de Paranapanema, SP, Cooperativa Holambra II. No momento da colheita, os frutos foram rigorosamente selecionados quanto ao estádio de amadurecimento (maturidade fisiológica), tamanho do fruto e ausência de defeitos.

A escolha destas cultivares, selecionadas pelo Instituto Agronômico de Campinas (Ojima et al., 1985, 1989), residiu em dois motivos. Primeiro, porque são as principais cultivares plantadas no Estado de São Paulo. De acordo com Agrianual (1997), as cultivares Aurora-1 e Aurora-2 correspondem a $30 \%$ da área cultivada com pessegueiros no Estado de São Paulo, enquanto Dourado-1 e 
Dourado-2 correspondem a 20\% dessa área. Depois por serem cultivares de meia-estação, suas épocas de produção coincidem com o pico de safra de pêssegos em São Paulo.

No primeiro experimento, em cada cultivar foram estudadas três temperaturas $\left(0,3\right.$ e $\left.6^{\circ} \mathrm{C}\right)$ e quatro períodos de armazenamento refrigerado (14, 21, 28 e 35 dias). Diante dos resultados do primeiro experimento, na safra seguinte foi instalado um segundo experimento, em que foram estudadas duas temperaturas $\left(0\right.$ e $\left.3^{\circ} \mathrm{C}\right)$ e cinco períodos de armazenamento $(7,14,21,28$ e 35 dias). Cada parcela com seis frutos foi acondicionada em sacos de polietileno perfurados, e armazenada em câmaras de refrigeração do tipo BOD, marca Marconi, modelo MA 415, previamente ajustadas para as devidas temperaturas.

$\mathrm{O}$ delineamento experimental adotado foi o inteiramente ao acaso, em esquema fatorial $3 \times 4$, no primeiro experimento, e $2 \times 5$ no segundo experimento, cada um com quatro repetições e parcelas de seis frutos.

Depois de retirados da câmara de refrigeração, os frutos, ainda embalados em sacos de polietileno, foram mantidos a $25^{\circ} \mathrm{C}$ por dois dias, com o objetivo de simular um período extra de tempo necessário à comercialização. As avaliações das características físico-químicas dos frutos foram realizadas no momento da instalação do experimento, visando a caracterizar o lote experimental, e após cada período de armazenamento, seguido do período simulado de comercialização. A firmeza da polpa foi avaliada com penetrômetro manual, Efegi, modelo FT-327 com ponteira 5/16", tomando-se duas leituras em lados opostos do fruto, e expressa em N. O teor de sólidos solúveis totais (SST) no suco foi determinado com refratômetro ATTO-2WAJ e expresso em ${ }^{\circ}$ Brix. A acidez total titulável (ATT) foi determinada por titulometria, segundo Carvalho et al. (1990). A coloração de fundo foi determinada com colorímetro Minolta CR-300 (escala L, C, ${ }^{\circ}$ h), efetuando-se duas leituras por fruto.

As amostras do mesocarpo dos frutos para as análises anatômicas, realizadas por microscopia de luz e de fluorescência (Luza et al., 1992), foram coletadas no momento da instalação do experimento, na retirada da câmara de refrigeração, e após cada período simulado de comercialização. As análises anatômicas auxiliam na determinação da fase crítica do armazenamento, ou seja, em que estádio do armazenamento a estrutura interna do fruto é afetada, além de permitir verificar se há alguma alteração estrutural, mesmo que o fruto não apresente sintomas de lanosidade durante o armazenamento.

Os dados coletados foram submetidos à análise de variância (teste F), e as médias, comparadas pelo teste de Tukey a $5 \%$ de probabilidade.

\section{Resultados e Discussão}

\section{Primeiro experimento}

Considerando que no 35으 dia de armazenamento a $6^{\circ} \mathrm{C}$ os pêssegos das duas cultivares apresentavam-se excessivamente maduros, sem condições de comercialização, esses frutos não foram submetidos às análises previamente delineadas.

Todas as variáveis físico-químicas analisadas alteraram-se em relação aos valores obtidos no momento da colheita. Entretanto, a análise de variância não apresentou interação significativa entre os fatores período e temperatura de armazenamento, em nenhuma das variáveis analisadas.

A perda de matéria fresca de ambas as cultivares, embora tenha aumentado durante o armazenamento, foi muito pequena, chegando a valores médios de $4 \%$ ao final do período de armazenamento (Figura 1). Sabe-se que até $5 \%$ de perda de matéria fresca, os pêssegos não apresentam sinais de murchamento e perda da consistência que comprometam sua qualidade e comercialização (Kluge et al., 1997). Apenas os pêssegos 'Aurora-1' apresentaram perda de matéria fresca significativamente influenciada pela temperatura, isto é, o armazenamento a $6^{\circ} \mathrm{C}$ resultou em maior perda de matéria fresca, quando comparado com o armazenamento a 0 e $3^{\circ} \mathrm{C}$, principalmente após os 28 dias.

O teor de sólidos solúveis totais (SST) nos pêssegos 'Aurora-1' foi também influenciado de modo significativo pelo período e temperatura de armazenamento. Os maiores incrementos ocorreram durante o período inicial de 21 dias de armazenamento refrigerado, quando atingiram um pico médio de $10,2^{\circ}$ Brix, e diminuíram posteriormente (Figura 1 ). Normalmente, o teor de sólidos solúveis aumenta com o amadurecimento, por causa dos processos de biossíntese ou degradação de polissacarídeos, até a fase em que o fruto passa a utilizar essa reserva de açúcares para manter sua atividade metabólica (Chitarra \& Chitarra, 1990; Gottinari et al., 1998). Na cultivar Dourado-2, o teor de SST foi influenciado significativamente apenas pela temperatura de armazenamento. As duas cultivares apresentaram teores de SST mais elevados quando armazenados a $0^{\circ} \mathrm{C}$ (Figura 1), fato que pode ser atribuído à menor taxa respiratória dos frutos. 
As diferenças nos teores de acidez total titulável (ATT) ao longo do armazenamento foram pequenas, e as duas cultivares mostraram pequenos decréscimos nos teores de acidez durante o armazenamento (Figura 1), o que pode ser explicado pelo processo de oxidação. Chapman \& Horvat (1990) também concordam que os teores de ácido cítrico em pêssegos diminuem à medida que os frutos amadurecem. $\mathrm{Na}$ cultivar Dourado-2, essa redução foi mais acentuada aos 28 dias de armazenamento a 3 e $6^{\circ} \mathrm{C}$ (Figu-

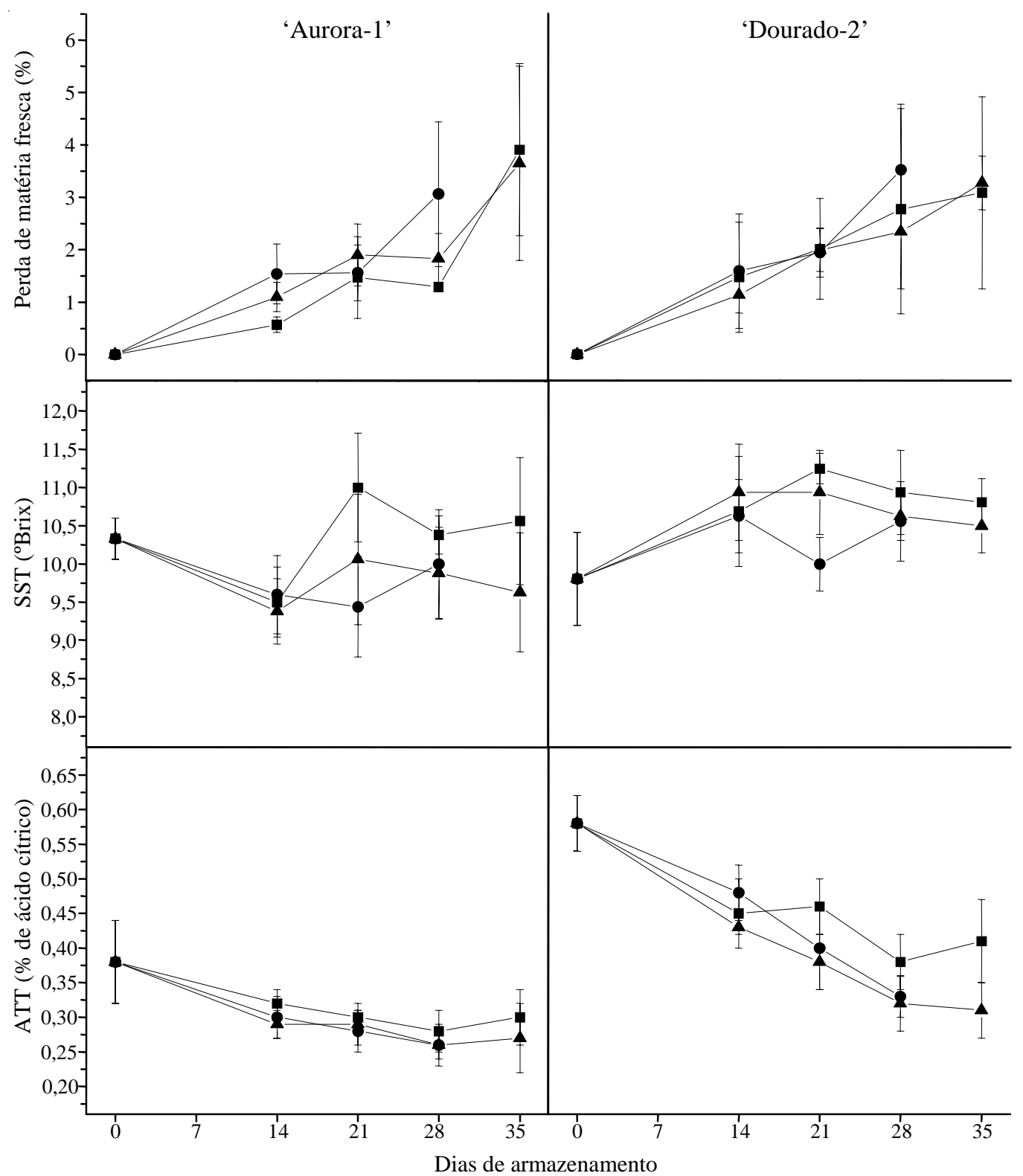

Figura 1. Influência da temperatura $\left(0^{\circ} \mathrm{C}: \square ; 3^{\circ} \mathrm{C}: \mathbf{\Lambda} ; 6^{\circ} \mathrm{C}: \bullet\right)$ e do período de armazenamento, seguido de dois dias de simulação à comercialização sob $25^{\circ} \mathrm{C}$, na perda de matéria fresca, sólidos solúveis totais (SST), e acidez total titulável (ATT) de pêssegos 'Aurora-1' e 'Dourado-2'. Barras verticais indicam o desvio-padrão da média $(n=4)$. 
ra 1). Os teores de acidez em pêssegos Aurora-1 não foram significativamente influenciados pelas diferentes temperaturas de armazenamento.

$\mathrm{O}$ ângulo de cor $\left({ }^{\circ} \mathrm{h}\right)$ é uma medida apropriada para expressar a variação da coloração em produtos vegetais, em que o ${ }^{\circ} \mathrm{h}$ é de $90^{\circ}$ na amarela e de $180^{\circ}$ na verde. Durante o armazenamento, ambas as cultivares apresentaram decréscimos nos valores de ${ }^{\circ} \mathrm{h}$, ou seja, no desenvolvimento da cor amarela, principalmente após os 28 dias (Figura 2). Geralmente, o ${ }^{\circ} \mathrm{h}$ da epiderme dos frutos diminui à medida que se prolonga o armazenamento (Robertson et al., 1992). Essa mudança na coloração é atribuída tanto à degradação da clorofila quanto à síntese de carotenóides (Chitarra \& Chitarra, 1990). A coloração das duas cultivares foi significativamente influenciada pela temperatura. As temperaturas de 0 e $3^{\circ} \mathrm{C}$ foram mais eficientes na manutenção da coloração dos frutos, em comparação com a temperatura de $6^{\circ} \mathrm{C}$ (Figura 2), o que pode ser explicado pelo menor metabolismo dos frutos nessas temperaturas.

As duas cultivares apresentaram redução na firmeza da polpa após o armazenamento refrigerado, e na cultivar Dourado-2 esta redução foi mais drástica, em decorrência do estresse causado pelo frio (Figura 2).

Os pêssegos 'Aurora-1', que no momento da instalação do experimento tinham valores médios de firmeza de $34,6 \mathrm{~N}$, sofreram redução média de $40 \%$ ao final dos 35 dias de armazenamento, atingindo valores médios de 20,8 N (Figura 2). Apesar da redução na firmeza, esse amolecimento da polpa parece que não comprometeu a qualidade dos frutos para o consumo.

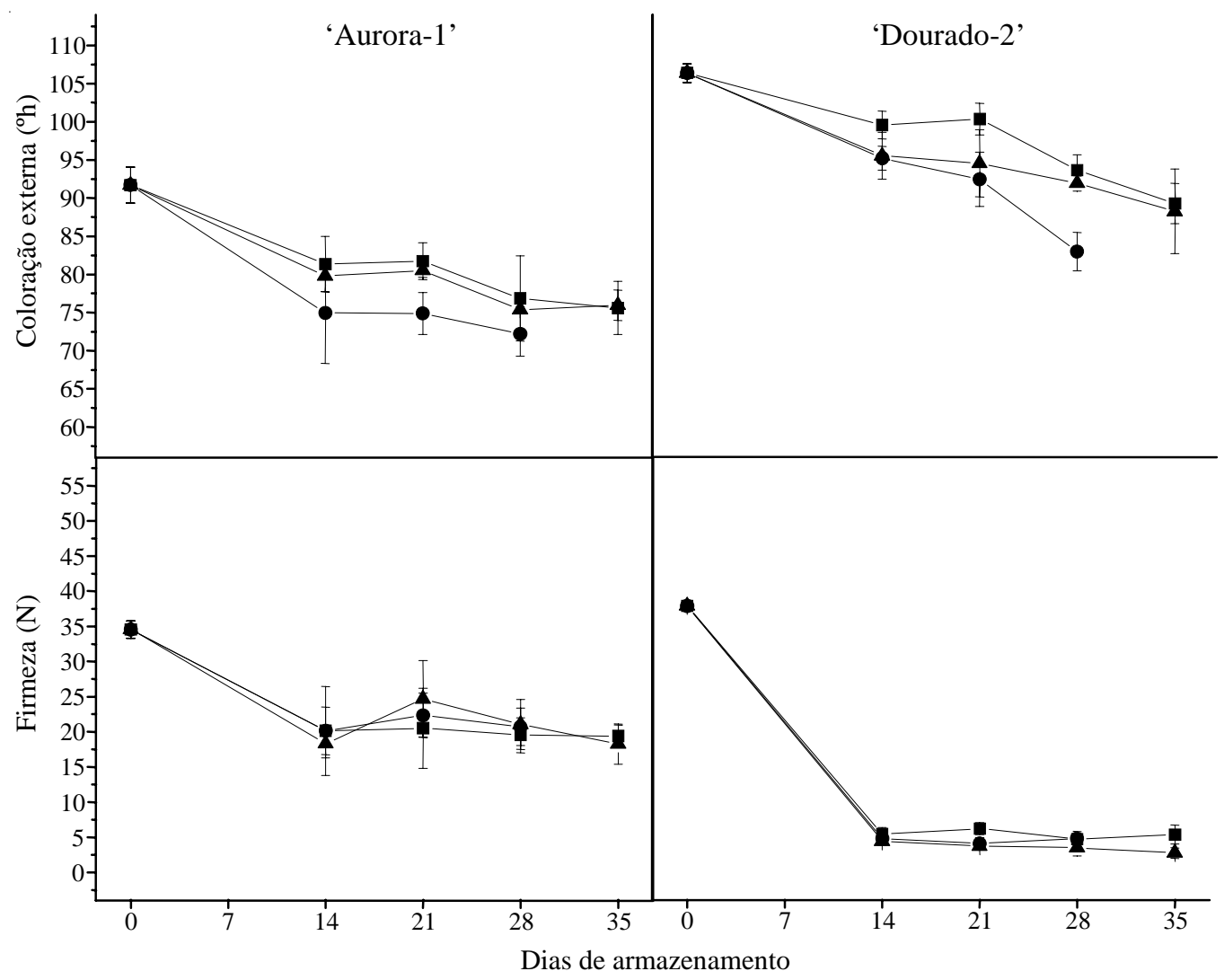

Figura 2. Influência da temperatura $\left(0^{\circ} \mathrm{C}: \mathbf{\square} ; 3^{\circ} \mathrm{C}: \mathbf{\Delta} ; 6^{\circ} \mathrm{C}: \bullet\right)$ e do período de armazenamento, seguido de dois dias de simulação à comercialização sob $25^{\circ} \mathrm{C}$, na coloração externa e firmeza da polpa de pêssegos 'Aurora-1' e 'Dourado-2'. Barras verticais indicam o desvio-padrão da média $(\mathrm{n}=4)$. 
Nos pêssegos 'Dourado-2', apesar da maior retenção da firmeza a $0^{\circ} \mathrm{C}$ em relação aos tratamentos com 3 e $6^{\circ} \mathrm{C}$, em todas as temperaturas a perda da firmeza foi extremamente alta (Figura 2). Esses pêssegos, que no momento da colheita apresentavam firmeza de $37,9 \mathrm{~N}$, atingiram reduções médias de $88 \%$, ou seja, valores médios de 4,5 $\mathrm{N}$ ao final do período de armazenamento, o que impossibilitaria o seu transporte, comercialização e consumo. A queda acentuada da firmeza dos pêssegos 'Dourado-2', que foi observada já no $14^{\circ}$ dia de armazenamento, teve como causa o estresse causado pelo frio. A exposição dos frutos a temperaturas que causam o "chilling" é o fator causador de mudanças na atividade normal das enzimas pectinametilesterase (PME) e poligalacturonase (PG). Uma atividade mínima basal da PME é mantida, levando ao constante acúmulo de substâncias pécticas desesterificadas, enquanto a atividade da PG, principalmente a da endo-PG, diminui drasticamente e não permite que essas substâncias sejam degradadas (Fernández-Trujillo et al., 1998; Zhou et al., 2000). Essas substâncias pécticas desesterificadas, de alto peso molecular, têm a capacidade de reter água, formando gel que leva ao decréscimo da firmeza e outras mudanças na textura da polpa, conhecida como lanosidade (Ben-Arie \& Sonego, 1980). Em trabalho com armazenamento refrigerado de pêssegos, Von Mollendorff \& Villiers (1988) relacionaram a queda brusca na firmeza da polpa dos frutos com o surgimento da lanosidade. Gottinari et al. (1998) também constataram que o estresse causado pelo frio foi a causa de uma perda de firmeza de $77 \%$ em pêssegos BR1 conservados a $0^{\circ} \mathrm{C}$ por 28 dias. Jackman et al. (1992) também relacionaram o decréscimo de firmeza na textura dos frutos de tomate ao "chilling".

Quanto às características anatômicas pesquisadas, o mesocarpo dos frutos das cultivares Aurora-1 e Dourado-2, no momento da colheita (controle), apresentava células parenquimáticas isodiamétricas de tamanhos distintos. As células eram túrgidas e arranjadas, e deixavam amplos espaços intercelulares (Figura 3).

Inicialmente, foram caracterizadas as alterações anatômicas de frutos armazenados a $3^{\circ} \mathrm{C}$. O mesocarpo dos frutos 'Aurora-1' e 'Dourado-2', armazenados por 14, 21, 28 e 35 dias, foi muito semelhante, permanecendo praticamente inalterado durante o armazenamento a $3^{\circ} \mathrm{C}$. Este resultado indica que o metabolismo do fruto também não sofreu alterações durante o período de armazenamento refrigerado, e o sintoma de lanosidade não foi observado.

Quando os frutos da cultivar Dourado-2 foram transferidos para a temperatura de $25^{\circ} \mathrm{C}$, por dois dias, após a remoção do armazenamento refrigerado a $3^{\circ} \mathrm{C}$ (período de simulação à comercialização) foi possível identificar alguns sintomas típicos da lanosidade. Nos frutos armazenados por $14+2$ e $21+2$ dias, foi observado acúmulo de substâncias pécticas nos espaços intercelulares e no interior das células parenquimáticas próximas aos feixes vasculares (Figura 4). Aos $28+2$ dias e aos 35+2 dias, este acúmulo expandiu-se para o restante do mesocarpo. Algumas células parenquimáticas apresentavam contorno irregular, fragmentação nuclear e perda de adesão entre paredes celulares adjacentes, que ampliam os espaços intercelulares, os quais eram preenchidos por substâncias pécticas (Figuras 5, 6 e 7). Tais substâncias são caracterizadas pelo baixo grau de esterificação e alto peso molecular, e por esse motivo, têm a capacidade de se ligar à água livre dos tecidos, e formar gel (Buescher \& Furmanski, 1978;

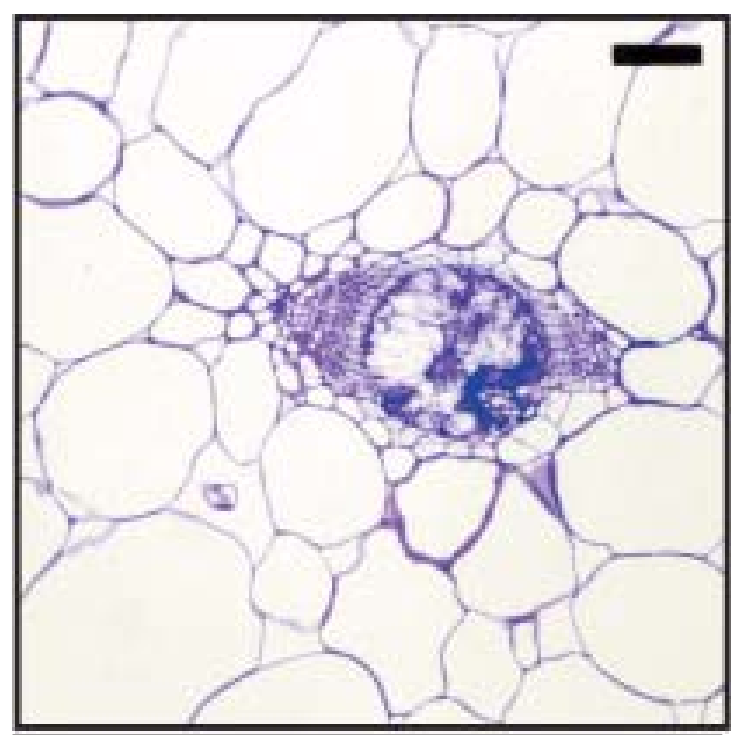

Figura 3. Corte transversal do mesocarpo de pêssego 'Dourado-2' no momento da colheita (controle). Barra $=74 \mu \mathrm{m}$. 


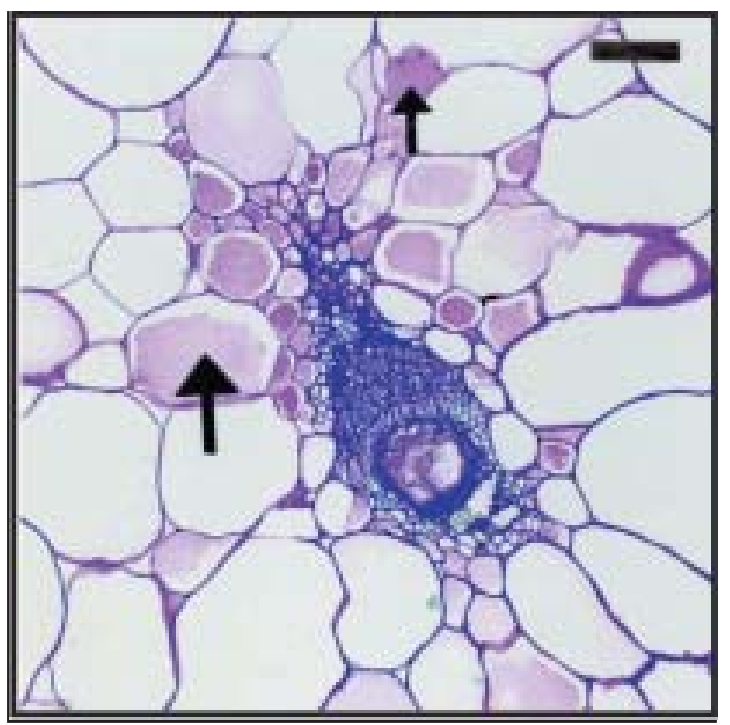

Figura 4. Corte transversal do mesocarpo de pêssego 'Dourado-2' após 14 dias de armazenamento a $3^{\circ} \mathrm{C}$, seguido de dois dias de simulação à comercialização sob $25^{\circ} \mathrm{C}$. As setas maior e menor indicam as substâncias nas células e nos espaços intercelulares, respectivamente. Barra $=74 \mu \mathrm{m}$.

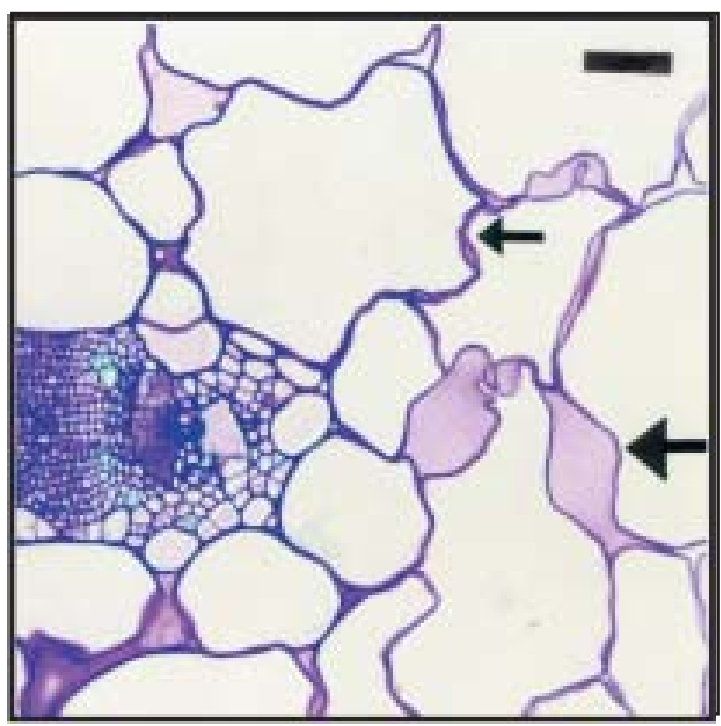

Figura 5. Corte transversal do mesocarpo de pêssego 'Dourado-2' após 28 dias de armazenamento a $3^{\circ} \mathrm{C}$, seguido de dois dias de simulação à comercialização sob $25^{\circ} \mathrm{C}$. Observar o afastamento das paredes de células adjacentes e o acúmulo de substâncias pécticas nos espaços intercelulares (seta maior), e o contorno irregular das células (seta menor). Barra $=37 \mu \mathrm{m}$.

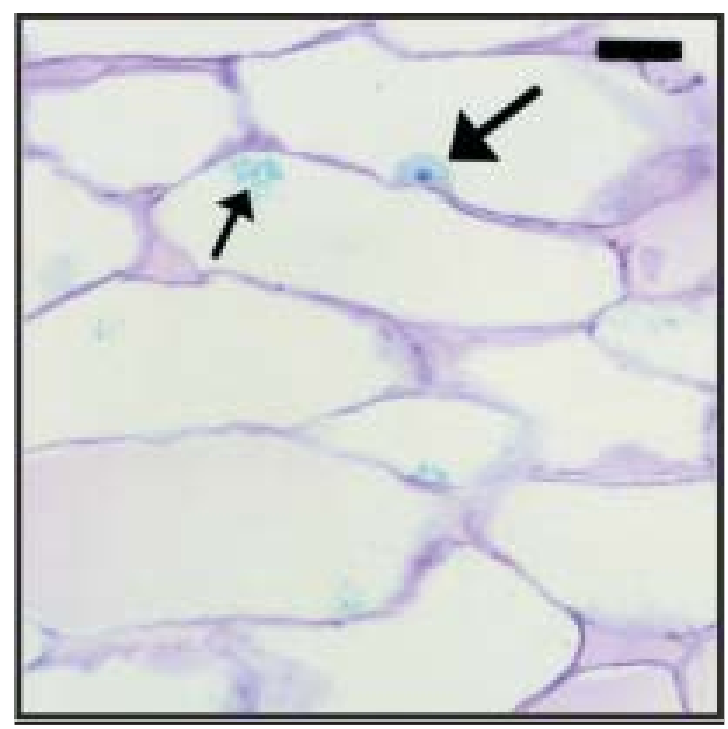

Figura 6. Corte transversal do mesocarpo de pêssego 'Dourado-2' após 35 dias de armazenamento a $3^{\circ} \mathrm{C}$, seguido de dois dias de simulação à comercialização sob $25^{\circ} \mathrm{C}$. Detalhe das células do mesocarpo exibindo processo de fragmentação nuclear. A seta maior indica o núcleo íntegro, e a seta menor, um dos núcleos fragmentados. Barra $=37 \mu \mathrm{m}$.

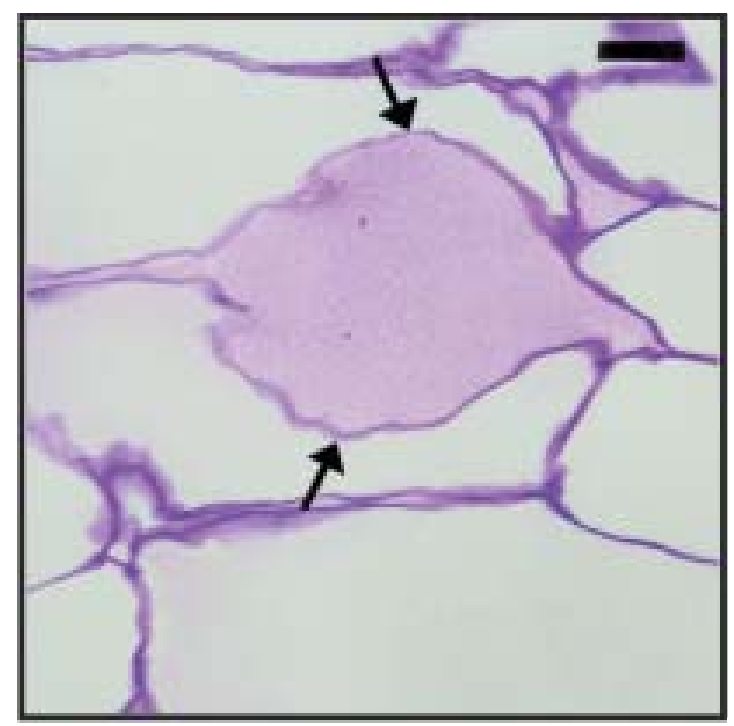

Figura 7. Corte transversal do mesocarpo de pêssego 'Dourado-2' após 28 dias de armazenamento a $3^{\circ} \mathrm{C}$, seguido de dois dias de simulação à comercialização sob $25^{\circ} \mathrm{C}$. Detalhe das células do mesocarpo exibindo afastamento entre as paredes celulares (setas), ampliando os espaços intercelulares que são preenchidos por substâncias pécticas. Barra $=37 \mu \mathrm{m}$. 
Ben-Arie \& Sonego, 1980; Lill et al., 1989). A formação do gel explica a perda da sucosidade e firmeza da polpa (Figura 2). Luza et al. (1992) e Brovelli et al. (1998), estudando as modificações anatômicas em pêssegos com lanosidade, verificaram os mesmos tipos de alterações.

A presença de substâncias pécticas no interior das células parenquimáticas, assim como a fragmentação nuclear, podem ser conseqüência de mudanças na integridade física da membrana plasmática e do envelope nuclear. Segundo Marangoni et al. (1989), a resposta primária aos ferimentos causados pelo frio é a alteração na fluidez da membrana lipídica, que passa da fase líquido-cristalina para gel sólida. Essa mudança na fluidez é a causa da alteração na permeabilidade das membranas celulares e sua conseqüente degradação.

O mesocarpo dos frutos 'Aurora-1', na comercialização simulada, apresentou as mesmas características anatômicas verificadas durante o armazenamento refrigerado a $3^{\circ} \mathrm{C}$. Não foi observado o acúmulo de substâncias pécticas no interior das células e dos espaços intercelulares, nem a separação da parede de células adjacentes, típicos sintomas de lanosidade encontrados em frutos 'Dourado-2'.

O comportamento de pêssegos 'Dourado-2' armazenados a $0^{\circ} \mathrm{C}$, por $14,21,28$ e 35 dias, foi semelhante ao de frutos armazenados a $3{ }^{\circ} \mathrm{C}$.

\section{Segundo experimento}

Como no primeiro experimento a lanosidade já era identificada em pêssegos 'Dourado-2' armazenados por 14 dias (primeira avaliação), com queda brusca na firmeza nesse período (Figura 2), neste experimento, as análises físico-químicas e anatômicas foram realizadas também no sétimo dia de armazenamento, visando determinar o período exato da manifestação desse distúrbio fisiológico. Uma vez que no primeiro experimento apenas a firmeza da polpa teve relação com o aparecimento da lanosidade, no segundo experimento serão apresentados apenas os resultados da análise dessa variável.

Pêssegos da cultivar Aurora-1 continuaram não apresentando sintomas de "chilling" até os 35 dias de armazenamento em ambas temperaturas estudadas. Em pêssegos 'Dourado-2', armazenados por sete dias a $0^{\circ} \mathrm{C}$, nenhum sintoma de "chilling" pôde ser observado, ao contrário dos armazenados a $3^{\circ} \mathrm{C}$, que após sete dias apresentavam queda brusca na firmeza (Figura 8), e ausência de sucosidade na polpa. A partir do 140 dia de armazenamento, os frutos apresentaram lanosidade nas duas temperaturas estudadas. Luchsinger \& Walsh (1998) relatam a manifestação mais precoce da lanosidade em frutos armazenados em temperaturas mais elevadas. Esses autores constataram que pêssegos armazenados a $0^{\circ} \mathrm{C}$ apresentaram esse sintoma mais tardiamente do que os pêssegos armazenados a $5^{\circ} \mathrm{C}$.

Esse resultado foi confirmado com a análise anatômica, que evidenciou que, mesmo após o período de comercialização simulada, as células do mesocarpo de pêssegos armazenados por sete dias a $0^{\circ} \mathrm{C}$ não apresentavam alterações típicas da lanosidade, enquanto frutos armazenados por $7+2$ dias a $3^{\circ} \mathrm{C}$ apresentavam acúmulo de substâncias pécticas próximo aos feixes, o que explica a ausência de sucosidade e a queda brusca de firmeza da polpa.

A análise ao microscópio de fluorescência das seções do mesocarpo coradas com corifosfina confirma que as substâncias amorfas presentes nos espaços intercelulares do mesocarpo de frutos com lanosidade eram de natureza péctica (Figura 9).

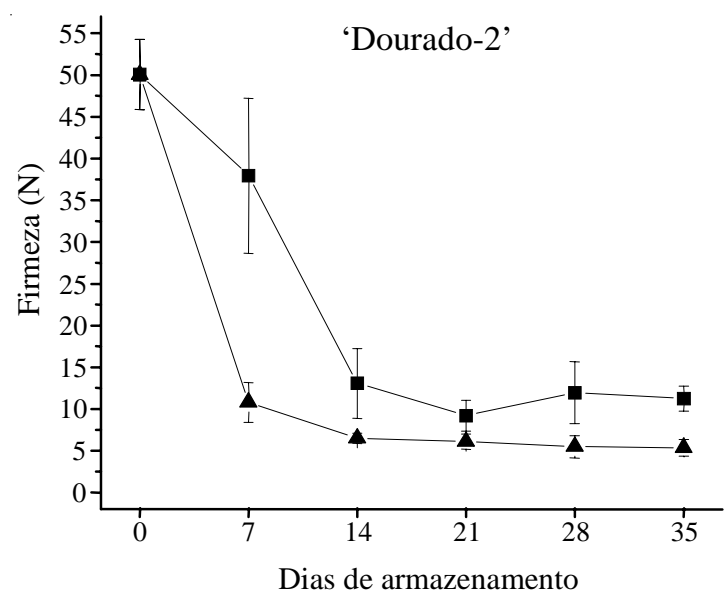

Figura 8. Influência da temperatura $\left(0^{\circ} \mathrm{C}: \mathbf{\square} ; 3^{\circ} \mathrm{C}\right.$ : $\left.\mathbf{\Delta}\right)$ e do período de armazenamento, seguido de dois dias de simulação à comercialização sob $25^{\circ} \mathrm{C}$, na firmeza da polpa de pêssegos 'Dourado-2'. Barras verticais indicam o desviopadrão da média $(n=4)$. 


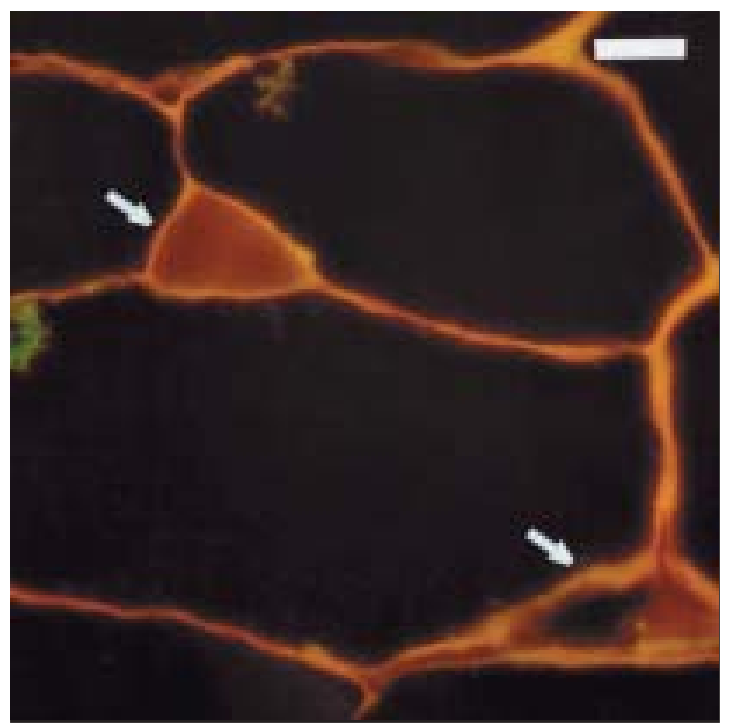

Figura 9. Corte transversal do mesocarpo de pêssegos 'Dourado-2', corados com corifosfina e analisados ao microscópio de fluorescência, após 35 dias de armazenamento a $3^{\circ} \mathrm{C}$, seguido de dois dias de simulação à comercialização sob $25^{\circ} \mathrm{C}$. Fluorescência nos espaços intercelulares (setas), indicam a presença de substâncias pécticas. Barra $=22,7 \mu \mathrm{m}$.

\section{Conclusões}

1. Os pêssegos das cultivares Aurora-1 e Dourado-2 diferem entre si quanto à sensibilidade ao armazenamento refrigerado.

2. Pêssegos da cultivar Aurora-1 podem ser conservados por até 35 dias, à temperatura de 0 ou $3^{\circ} \mathrm{C}$, sem comprometer a qualidade dos frutos.

3. Pêssegos da cultivar Dourado-2 são sensíveis ao armazenamento refrigerado, ou seja, apresentam sintomas de lanosidade após sete dias de armazenamento a $3^{\circ} \mathrm{C}$ e após 14 dias de armazenamento a $0^{\circ} \mathrm{C}$.

\section{Referências}

AGRIANUAL: anuário da agricultura brasileira. São Paulo: FNP Consultoria,1997. p. 85-94.

BEN-ARIE, R.; SONEGO, L. Pectolytic enzyme activity involved in woolly breakdown of stored peaches. Phytochemistry, Oxford, v. 18, n. 12, p. 2553-2555, 1980.
BRAMLAGE, W. J. Chilling injury of crops of temperate origin. HortScience, Alexandria, v. 17, n. 2, p. 165-168, 1982.

BROVELLI, E. A.; BRECHT, J. K.; SHERMAN, W. B.; SIMS, C. A. Anatomical and physiological responses of melting and nonmelting-flesh peaches to postharvest chilling. Journal of the American Society for Horticultural Science, Alexandria, v. 123, n. 4, p. 668674, 1998.

BRUHN, C. M.; FELDMAN, N.; GARLITZ, C.; HARDWOOD, J.; IVAN, E.; MARSHALL, M.; RILEY, A.; THURBER, D.; WILLIAMSON, E. Consumer perceptions of quality: apricots, cantaloupes, peaches, pears, strawberries, and tomatoes. Journal of Food Quality, Trumbull, v. 14, p. 187-195, 1991.

BUESCHER, R. W.; FURMANSKI, R. J. Role of pectinesterase and polygalacturonase in the formation of woolliness in peaches. Journal of Food Science, Chicago, v. 43, n. 1, p. 264-266, 1978.

CARVAlHO, C. R. L.; MANTOVANI, D. M. B.; CARVALHO, P. R. N.; MORAES, R. M. M. Análises químicas de alimentos. Campinas: Instituto de Tecnologia de Alimentos, 1990. 121 p.

CHAPMAN, G. W.; HORVAT, R. J. Changes in nonvolatile acids, sugars, pectin and sugar composition of pectin during peach (cv. Monroe) maturation. Journal of Agricultural and Food Chemistry, Washington, v. 38, n. 2, p. 383-387, 1990.

CHITARRA, M. I. F.; CHITARRA, A. B. Pós-colheita de frutos e hortaliças: fisiologia e manuseio. Lavras: Esal/ Faepe, 1990. 360 p.

CRISOSTO, C. H.; MITCHELL, F. G.; JU, Z. Susceptibility to chilling injury of peach, nectarine, and plum cultivars grown in California. HortScience, Alexandria, v. 34, n. 6, p. 1116-1118, 1999.

FERNÁNDEZ-TRUJILLO, J. P.; CANO, A.; ARTÉS, F. Physiological changes in peaches related to chilling injury and ripening. Postharvest Biology and Technology, Amsterdam, v. 13, n. 2, p. 109-119, 1998.

GALINDO, A. J. E.; CALERO, F. A.; VERA, J. G. M. Conservación frigorífica de melocotón y nectarina. Fruticultura Profesional, Barcelona, n. 50, p. 48-60, 1992.

GOTTINARI, R. A.; ROMBALDI, C. V.; SILVEIRA, P.; ARAÚJO, P. J. Frigoconservação de pêssego (Prunus persica (L.) Batsch) cv. BR1. Revista Brasileira de Agrociência, Pelotas, v. 4, n. 1, p. 47-54, 1998. 
JACKMAN, R. L.; GIBSON, H. J.; STANLEY, D. W. Effects of chilling on tomato fruit texture. Physiologia Plantarum, Copenhagen, v. 86, n. 2, p. 600-608, 1992.

KLUGE, R. A.; NACHTIGAL, J. C.; FACHINELLO, J. C.; BILHALVA, A. B. Fisiologia e manuseio pós-colheita de frutas de clima temperado. Pelotas: Ufpel, 1997. $163 \mathrm{p}$.

LILL, R. E.; O’DONAGHUE, E. M.; KING, G. A. Postharvest physiology of peaches and nectarines. Horticultural Reviews, New York, v. 11, p. 413-452, 1989.

LUCHSINGER, L. E.; WALSH, C. S. Chilling injury of peach fruit during storage. Acta Horticulturae, Leuven, n. 464 , p. $473-477,1998$.

LUZA, J. G.; GORSEL, R. van; POLITO, V. S.; KADER, A. A. Chilling injury in peaches: a cytochemical and ultrastructural cell wall study. Journal of the American Society for Horticultural Science, Alexandria, v. 117, n. 1, p. 114-118, 1992.

MARANGONI, A. G.; SMITH, A. K.; YADA, R. Y.; STANLEY, D. W. Ultrastructural changes associated with chilling injury in mature-green tomato fruit. Journal of the American Society for Horticultural Science, Alexandria, v. 114, n. 6, p. 958-962, 1989.

MORRIS, L. L. Chilling injury of horticultural crops: an overview. HortScience, Alexandria, v. 17, n. 2, p. 161162,1982
OJIMA, M.; CAMPO-DALL'ORTO, F. A.; BARBOSA, W.; MARTINS, F. P.; SANTOS, R. R.; RIGITANO, O. 'Aurora-1'e 'Aurora-2': novos cultivares de pêssego doce e polpa amarela. In: CONGRESSO BRASILEIRO DE FRUTICULTURA, 10., 1989, Fortaleza. Anais... Fortaleza: Sociedade Brasileira de Fruticultura, 1989. p. 422425.

OJIMA, M.; CAMPO-DALL'ORTO, F. A.; BARBOSA, W.; TOMBOLATO, A. F. C.; RIGITANO, O.; SCARANARI, H. J.; MARTINS, F. P.; SANTOS, R. R. 'Dourado-1' e 'Dourado-2': novos cultivares de pêssego amarelo para mesa. Bragantia, Campinas, v. 44, n. 1, p. 451-455, 1985.

ROBERTSON, J. A.; MEREDITH, F. I.; CHAPMAN, G. W.; SHERMAN, W. B. Ripening and cold storage changes in the quality characteristics of nonmelting clingstone peaches (FLA 9-20C). Journal of Food Science, Chicago, v. 57, n. 2, p. 462-465, 1992.

VON MOLLENDORFF, L. J.; JACOBS, G.; VILLIERS, O. T. de. Cold storage influences internal characteristics of nectarines during ripening. HortScience, Alexandria, v. 27, n. 12, p. 1295-1297, 1992.

VON MOLLENDORFF, L. J.; VILLIERS, O. T. de. Role of pectolytic enzymes in the development of woolliness in peaches. Journal of Horticultural Science, Ashford, v. 63, n. 1, p. $53-58,1988$.

ZHOU, H. W.; BEN-ARIE, R.; LURIE, S. Pectin esterase, polygalacturonase and gel formation in peach pectin fractions. Phytochemistry, Oxford, v. 55, n. 3, p. 191195, 2000. 